\title{
Diablotexto
}

\section{El reportaje gráfico: una alternativa del compromiso periodístico. Representación contextual y estrategias narrativas en Barcelona. Los vagabundos de la chatarra (2014)}

The Graphic Report: an Alternative of the Journalistic Commitment. Contextual Representation and Narrative Strategies. Los vagabundos de la chatarra (2014)

\section{THOMAS FAYE UNIVERSITÉ DE LIMOGES}

Resumen: En la producción reciente de novelas gráficas, la influencia del contexto social cobra una relevancia particular y creciente en de la construcción de la diégesis y en la elaboración de la estética iconotextual. A través de la denuncia, por Carrión y Sagar, de la precariedad de los ilegales que sobreviven del comercio clandestino de residuos, pretendemos explorar la especificidad de una escritura gráfica periodística marcada por su heterogeneidad y tratar, así, de comprender cómo los recursos narrativos y semióticos tradicionales de la representación iconotextual permiten renovar el tratamiento de hechos contextuales en un soporte híbrido, entre diégesis y mundo referencial.

Palabras clave: Novela gráfica, semiótica, iconotexto, chatarra, compromiso periodístico.

Abstract: In the recent production of graphic novels, the influence of the social context receive a particular and increasing relevancy, both as what the construction of diegesis and the elaboration of the iconotextual aesthetics concerns. Across the denunciation, by Carrión and Sagar, of the precariousness of the illegal ones that survive of the clandestine trade of residues, we aim to explore the specificity of a graphic journalistic writing marked by its heterogeneity and to understand how the traditional narrative and semiotic resources of the iconotextual representation permit to renew the treatment of contextual facts in a hybrid support, between diegesis and referential world.

Key words: Graphic Novel, Semiotics, Iconotext, Chatarra, Journalistic Commitment. 
24 de julio de 2013. "Continúa el drama humanitario en el barrio de Poblenou [...]. Esta vez, le ha tocado a la nave de la calle Puigcerdà, el asentamiento más grande de la ciudad [...]. Los Mossos d'Esquadra lo han desalojado esta mañana"1. ¿El escenario? La ciudad condal. ¿Los actores? Gitanos, rumanos, subsaharianos, organismos sanitarios, mafias. ¿El caso? La chatarra. El drama que relata eldiario.es también lo relatan Jorge Carrión y Sagar Forniés en un reportaje gráfico que demuestra, con Thierry Groensteen, que la escritura gráfica es "un arte del relato" (2005: 44). De la relación entre literatura gráfica e historia o actualidad, Elisa Bricco, en los Cahiers de Narratologie, sugiere pistas de intelección de la dialéctica factualidad / ficcionalidad por la aprensión de la tensión entre tema y medium. En esta encrucijada podría ubicarse el reportaje gráfico, o cómic de no ficción, como vía alternativa de acceso a problemáticas sociales. En Barcelona. Los vagabundos de la chatarra (Norma, 2015), Carrión y Sagar observan mutaciones: la de la chatarra, la de los chatarreros, la de Barcelona, cuestionando la relación entre texto y contexto, entre realidad, ficción y no ficción. Así, me propongo analizar cómo el iconotexto, reapropiado por el periodismo de investigación, se vale de recursos narrativos tradicionales para elaborar un espacio entre diégesis y mundo referencial propicio a la concientización y a la aparición de una praxis del compromiso. Examinando primero las pistas narrativas a la obra en el cómic, intentaré luego analizar las consecuencias de la diegetización de la voz periodística como vector de heterogeneidad estructural y así comentar la vía metarreflexiva que abre el noveno arte como nueva forma del compromiso.

\section{Una historia que acaba...}

La obra se abre con un prólogo con título "Esta historia es antigua y acaba mal". En primera persona del plural $^{2}$, es informativo, proléptico y programático y se

\footnotetext{
1 "Termina el desalojo de la nave del Poblenou, continúa el drama humanitario". http://www.eldiario.es/catalunya/Mossos-desalojan-ocupada-personas-Poblenou_0_157134334.html [29 de marzo 2016].

2 "Sagar y yo", "nos dedicamos", "donde vivimos" son ejemplos de esta saturación de la retórica de la subjetividad mediante el uso de la primera persona.
} 
articula en torno a la tesis defendida: "el progreso es un mito"3. El terreno de su estudio es una fábrica "okupada" de la calle Puigcerdà y su correspondiente mundo de la chatarra pronto designada como "banda sonora de la ciudad"4, lo cual ya abre la vía a la diegetización. Las cien páginas que siguen, de formato heterogéneo pero convencional, nos invitan a seguir a los autores, integrados en la diégesis con un estatuto inestable que analizaremos a continuación, en la pista de la chatarra por una Barcelona en mutación.

\section{Morfología general}

Entre las diferentes historias particulares que componen el relato se interponen muestras de una estética alternativa, como señales de una voluntad asumida de poner la realidad en perspectiva con los medios propios del iconotexto y establecer dos redes narrativas que se nutren la una de la otra: en tres ocasiones seguimos con el arquitecto Fermín Vázquez, desde un medallón incrustado, los avances de las obras del mercado de los Encantes Nuevos, donde se despacha parte de la chatarra.

\footnotetext{
3 "[...] el progreso es un mito inmaterial que deja a su paso un grueso y matérico rastro de mierda" (Carrión y Sagar: 5).

4 "El ruido de las ruedas de sus carritos de supermercado se ha convertido en la banda sonora de esta ciudad", (Carrión y Sagar: p.5).
} 


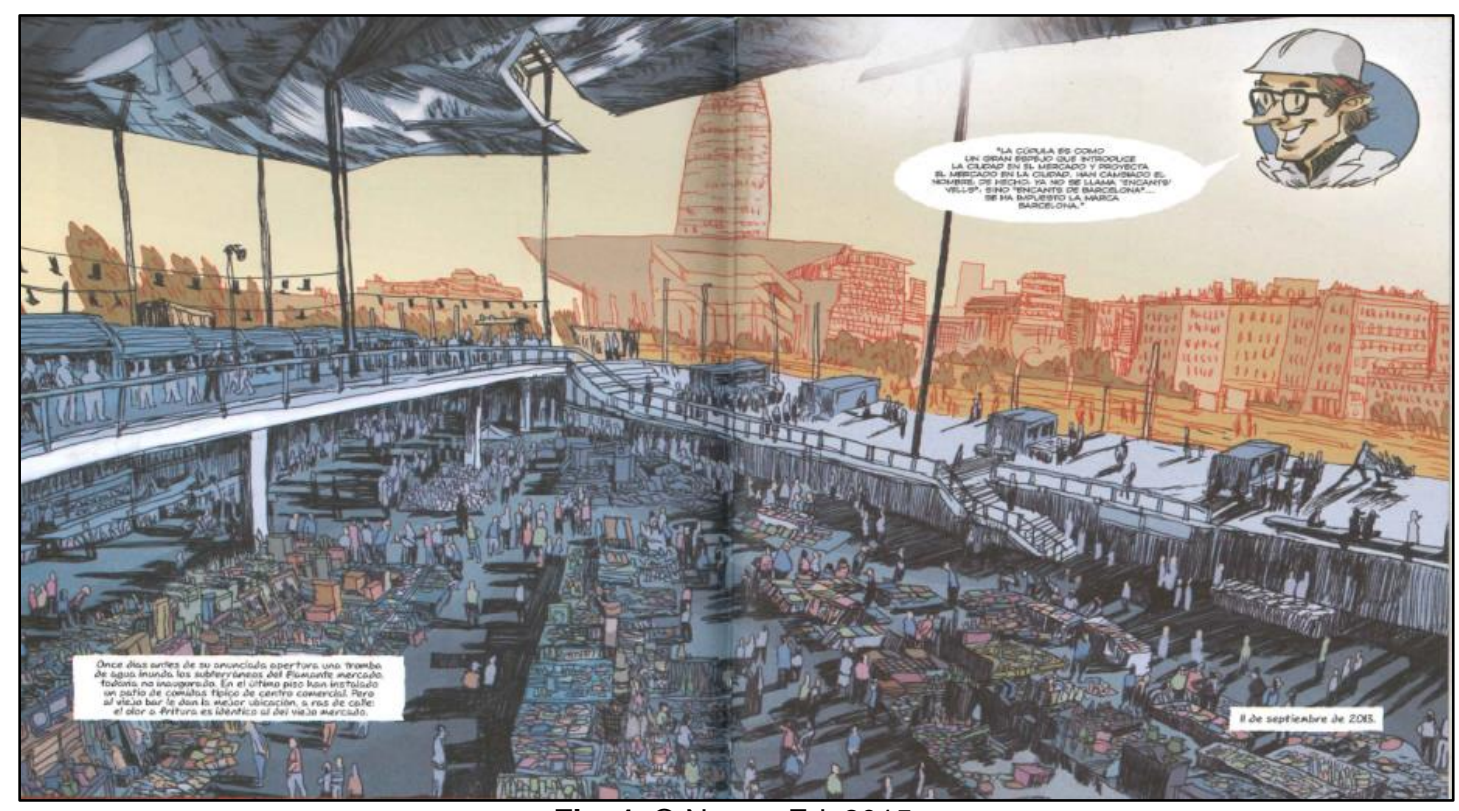

Fig. 1. ( ) Norma Ed. 2015.

La presencia de comillas dentro de los bocadillos mediatizan doblemente el discurso, asimilable a un discurso indirecto libre, que genera un proceso de abismación y desestabiliza las fronteras de la representación; en tres ocasiones, se nos brinda imágenes de Barcelona (un mapa Google Earth, un callejero esquemático, una escena callejera al pie de la torre Agbar) que acogen una representación iterativa de los periodistas en bici, como un desafío al cronotopo inicial; en tres ocasiones, se insertan páginas de cuaderno en las cuales unas fotos, reproducciones de páginas web o apuntes a mano con amarillo neón completan elementos del prólogo (cuyo título comparten) y establecen un puente entre la diégesis y el mundo referencial.

\section{Chatarra: objeto y sujeto}

Desde el principio del relato, el lector queda atrapado por un parto figurado que lo proyecta al mundo de la chatarra que lo arropa en una globalidad sinestésica ${ }^{5}$.

5 Al paso progresivo de la oscuridad a la luz se añade la referencia explícita al "ruido ensordecedor" del mismo modo que se solicita el tacto al evocar y representar el metal (Carrión y Sagar: 9). 


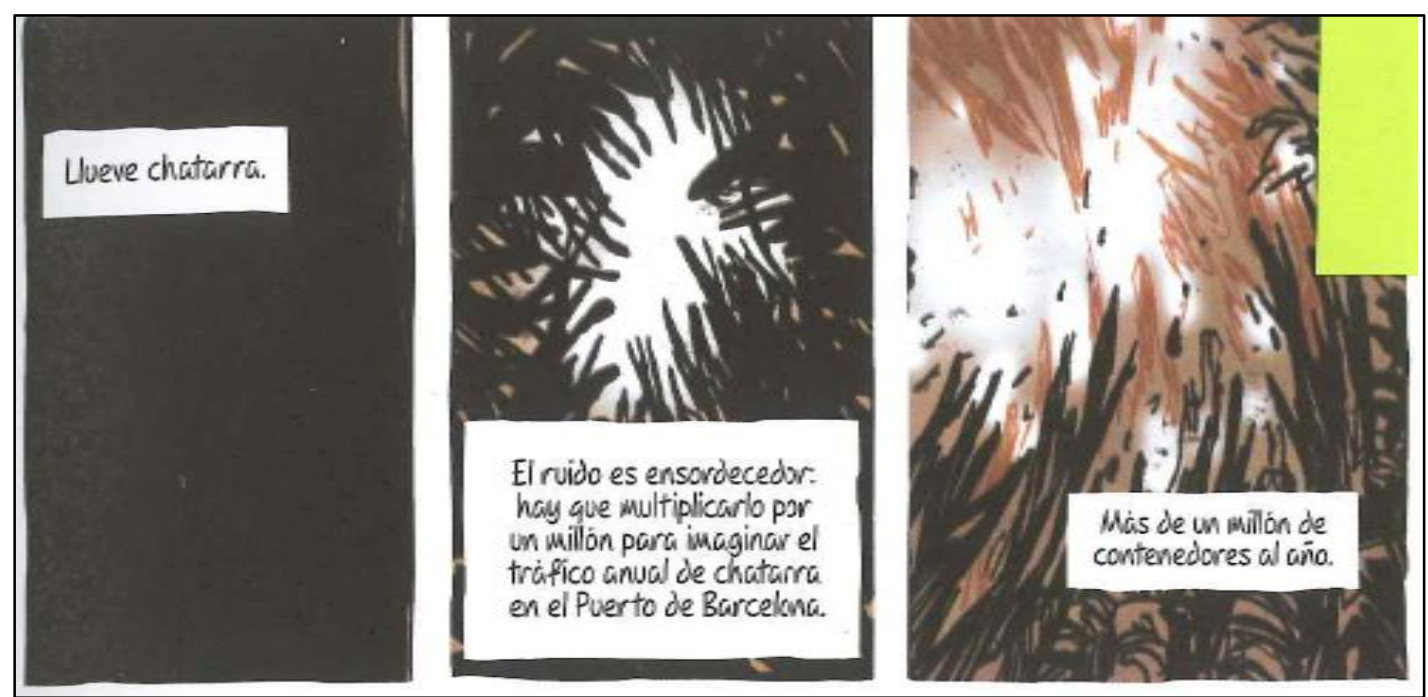

Fig. 2. () Norma Ed. 2015

Asimismo atrapa a Carrión y a Sagar, propulsados, por el efecto de profundidad del reparto viñetal, al corazón del cómic y al corazón del mundo chatarrero. Un mundo presentado como una verdad esencial más que literal (Sacco: $s / p)^{6}$, por sus lugares y los personajes que los ocupan. En cada descripción se recompone, mediante una selección estricta de indicios, un decorado sintético, paradójicamente generador de connotación: pintadas reales $^{7}$, crucifijos y alfombras de oración, una ambulancia cuando se cuestiona el papel de la Cruz Roja... que llegan a constituir un lugar ideal, receptáculo de individualidades indisociables de micro-espacios que legitiman la estructura viñetal $^{8}$. Abudu, por ejemplo, cuyos fragmentos se esparcen por su entorno, acaba recobrando unidad a medida que el trazado, siguiendo el acceso de violencia que lo arrebata, se hace más violento. El mundo chatarrero oscila entre disecciones casi naturalistas e impresionismo y crea una tensión narrativa coherente entre lo contado y la manera de hacerlo.

\section{"Effet de réel” y "New Journalism"}

\footnotetext{
${ }^{6}$ Sacco Joe, Reportages. Un manifeste, quelqu'un?

7 "No soy un animal, somos personas" (Carrión y Sagar: 37 ).

${ }^{8}$ André Helbo define el micro-espacio como aquel que está constituido por el contacto entre los personajes y que determina el formato de las viñetas.
} 
Los lugares exteriores también son significativos para apuntar, entre otros, la indigencia consecutiva a la modernización de la ciudad que irrumpe como protagonista. De elemento denotativo pronto adquiere el estatuto de objeto de observación antes de disolverse, inmediatamente, al convertirse —por el símil textual e intertextual con la Baltimore de la serie The Wire- en parangón de la ciudad carcomida por la corrupción. La relación del texto con la imagen ya no se define en términos de anclaje o relevo (Barthes, 1964: 44 y ss.) sino mediante la diegetización de la subjetividad. Es ahí donde irrumpe entonces el new journalism ${ }^{9}$ que, con el autor periodista Joe Sacco a su cabeza, pretende mostrar "una cruda realidad a menudo invisibilizada, aunque no invisible"10 e invita a cuestionar la noción de subjetividad. Al dejarle la palabra en el epílogo, Carrión y Sagar establecen un protocolo de lectura, fruto de selecciones narrativas y gráficas asumidas, fruto también de la diegetización de lo real y de la primacía del efecto de realidad, y crean así las condiciones de un periodismo de compromiso.

\section{Diegetización del periodismo: heterogeneidad de la reescritura gráfica}

Dicho periodismo de compromiso no solo se arraiga en el efecto de realidad expresado por la estética modernista de la grafiación ${ }^{11}$, sino que parece originarse en una renovación postmodernista de las pautas de la narración periodística tradicional.

\section{Ética de la entrevista}

\footnotetext{
9 “Ce journalisme popularisé par Hunter S. Thompson, qui se caractérise par un mélange de journalisme et d'autobiographie" (Gravett: 250).

$10 \mathrm{http}: / /$ saludytebeos.blogspot.com.es/2012/10/los-reportajes-de-joe-sacco.html/ [29 de marzo de 2016] Declara también, en el prológo a sus Reportajes: "Mon intention, en admettant que je suis présent dans la scène, est de signaler au lecteur que le journalisme est un processus pratiqué par un être humain, avec toutes les imperfections que cela implique. Ce n'est pas une expérience figée [...]" (Sacco: $s / p)$.

11 "La carencia misma de lo significado en provecho sólo del referente llega a ser el significado mismo del realismo: se produce un efecto de realidad fundamento de ese verosímil inconfesado que constituye la estética de todas las obras corrientes de la modernidad" (Barthes, 1968: 100).
} 
Investigar es entrevistar: a Toni el estibador, a Vasile el chatarrero rumano, a Pili la matriarca, a Juan el veterano, a Williams el artista o a Abudu-Kherama el senegalés. A este se le dedican 12 páginas marcadas por su gran coherencia narrativa y gráfica. Si bien Carrión impulsa el discurso ${ }^{12}$, Abudu es quien nos sume en su universo al pasar página ${ }^{13}$ : una leonera a oscuras, un caos íntimo en el cual se proyecta la representación fragmentada del chatarrero. El dibujante ha desaparecido, escindiendo la figura periodística ${ }^{14}$. El periodista escucha, callado mientras Abudu entrega su historia, sus miedos, sus luchas por los refugiados, sus rencores en unas láminas cuyo trazado parece desmembrar el cuerpo y que acompañan la violencia del propósito. La reaparición parcelaria de Carrión restablece una forma más convencional, aunque la presencia metonímica del dibujante — hecho ojo y mano— reafirma la presencia de un filtro que reequilibra lo dicho y lo mostrado. Ese mismo filtro es asumido de otra forma en la entrevista a Juan, el gitano-punk. El efecto de repetición marca una presencia escópica de la figura periodística que transmite su visión de una materia bruta. Entre "contexto" y "contextura" (Fresnault-Deruelle: 177), la construcción de las entrevistas y la red artrológica que elaboran funcionan a modo de descontextualización y diegetización del mundo referencial para que los chatarreros vayan adquiriendo una historia, una individualidad marcadas por una identidad iconotextual reconocible.

\footnotetext{
12 "Nos encantaría conocer tu vida y cómo fue que llegaste hasta aquí" (Carrión y Sagar: 41).

${ }^{13}$ En la viñeta inmediatamente anterior a la frase de Carrión, se puede ver un zoom sobre la llave de la nave en la cual está organizado el universo de Abudu.

${ }^{14}$ La desaparición de Sagar implica una escisión de la entidad periodística, al contrario de lo que pasa, por ejemplo, en la entrevista de Juan en la cual periodista y dibujante parecen adoptar una sola mirada.
} 

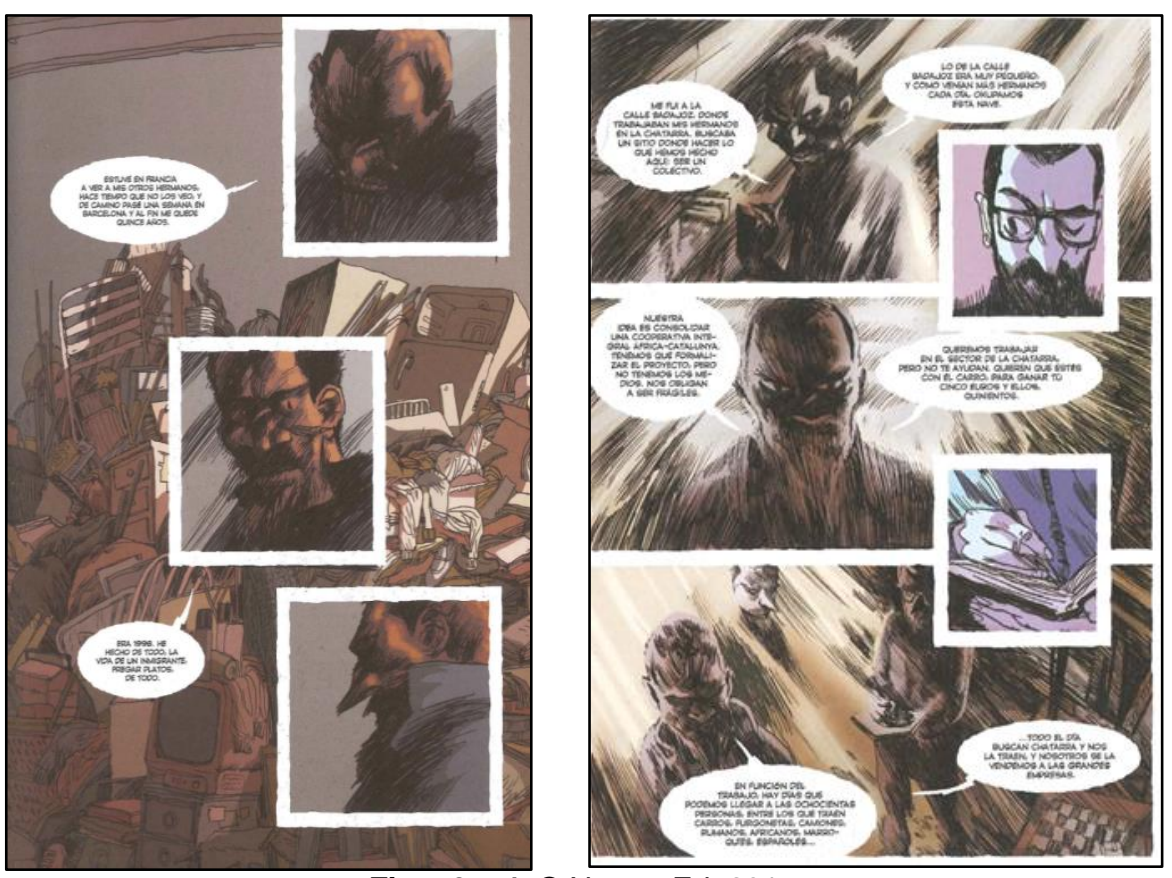

Figs. 3 y 4. ๑ Norma Ed. 2015

\section{El vértigo fotográfico}

"La imagen gráfica representa la apariencia de una irrealidad. La imagen fotográfica representa la apariencia de una realidad" (Xavier: 23) ${ }^{15}$. Esas palabras de José Manuel Xavier parecen haber inspirado a Carrión y Sagar en su uso de la foto como legitimación problemática del proyecto gráfico. Al negarse con vehemencia a que les saquen fotos ${ }^{16}$, los chatarreros declaran el arte fotográfico como comprometido y peligroso. Por cierto, la obra dedica una atención particular a la cámara como objeto: garante de realismo —un periodista de verdad lleva cámara - su vínculo simbólico con la verdad es fuente de reacciones violentas, traducidas por procesos de abismación, de fragmentación de la acción o incluso de desdoblamiento del punto de vista (véase, por ejemplo, la página 57), pasando a sacralizar indirectamente la técnica del dibujo ${ }^{17}$. La foto se inscribe así en una dialéctica de atracción / repulsión que parece preocupar a los autores, hasta el punto de dibujar fotos en ocasiones. Ahora bien, la reflexión

\footnotetext{
15 Traducimos nosotros.

${ }^{16}$ Véase Carrión y Sagar: 56 y ss.

${ }^{17}$ En este misma escena, doña Pili, da su visto bueno para que Sagar dibuje lo que le apetezca con tal de que pida permiso.
} 
sobre el valor de la foto culmina en el episodio que relata el desalojo de dos naves ${ }^{18}$.

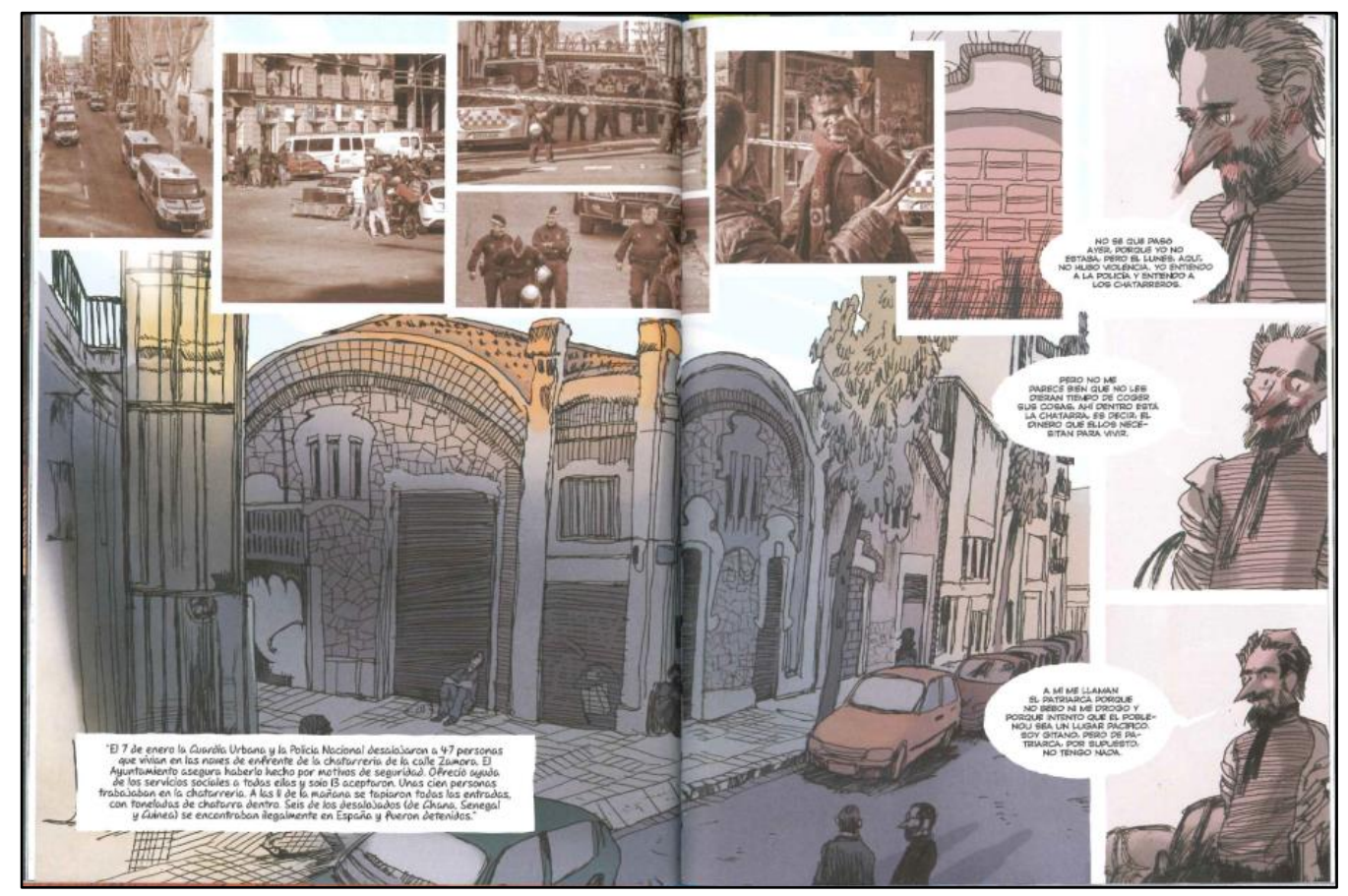

Fig. 5. () Norma Ed. 2015.

Para guiar al lector en el recorrido que del abandono de una calle va a la desolación de otra, el lector cuenta con los recitativos, la inserción de un fragmento de prensa o las explicaciones de "El Patriarca". Y aquí irrumpen fotos, capaces de "transmitir la información (literal)", con su valor de "registro" más que de "transformación", portadoras de un "mito del natural" (Barthes, 1964: 46 y ss.). La mímesis impulsada instaura una suspensión de la narración catártica. Se reafirma el estatuto de no ficción de la obra y cualquier brote de conciencia ficcional es aniquilado en beneficio de una conciencia espectatorial que se manifiesta por una vuelta a una relación iconotextual de anclaje más tradicional.

\section{Modernidad virtual}

\footnotetext{
${ }^{18}$ El desalojo de la nave de la calle Zamora y el de la nave de la calle Sancho de Ávila se cuentan en las páginas 62 a 65.
} 
Las citas de internet vienen a rematar la heterogeneidad del efecto de realidad del cómic. Me centraré por ahora en el uso diegético hecho de los tuits oficiales del Ayuntamiento de Barcelona.

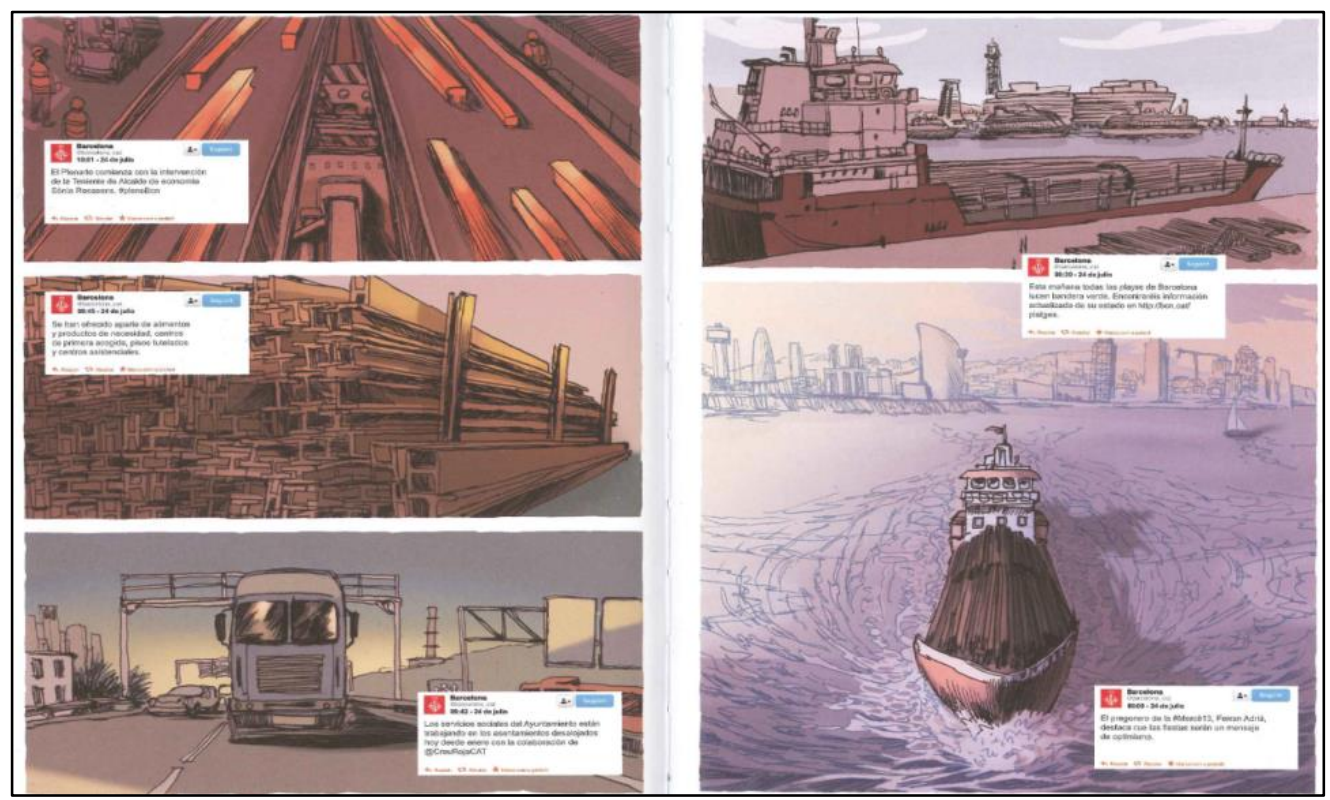

Fig. 6. () Norma Ed. 2015

Tras la evacuación de la nave de la calle Puigcerdà, la narración nos lleva en pos de una bolsa de escombros con la cual recorremos el trayecto de la chatarra, de su recolección a su transformación y comercialización. Las viñetas, alargadas y cromáticamente significantes, sintetizan metafóricamente el desalojo y traslado de los chatarreros que evoca explícitamente una serie de tuits, índices de modernidad, con los cuales el Plenario legitima la orden de expulsión. La reproducción de esos tuits según una cronología invertida (de las 13 '28 a las 8) hace que se choquen en la diégesis dos temporalidades que hacen cínicamente manifiesta la incomprensión entre los que preconizan el reciclaje como fuerza de vitalidad e integración y los que resultan excluidos de este círculo

\section{Metarreflexión y formas del compromiso}

Al pregonar que "es una historia [...] que acaba mal", el prólogo invita a una lectura retroactiva y valoriza al epílogo, receptáculo de las claves de un texto que 
se desdobla para crear la distancia suficiente al análisis de la circularidad agobiante del progreso.

\section{Arte y compromiso}

La intertextualidad impera en el texto, del mero guiño a Steinbeck en el título ${ }^{19}$ al paralelismo con la serie The Wire, pasando por epígrafes de Varda o Benjamín. Esas referencias traducen el impacto del arte en la reflexión de Carrión y Sagar en el momento de la génesis del texto. Un impacto orgánico cuando contribuye a retratar a los testigos en la complejidad de sus trayectorias vitales (Abudu posee "un Picasso, y [...] otras joyas"; Williams se reivindica artista completo por la fuerza ${ }^{20}$ ) como si el arte reuniera afán vitalista y futilidad ${ }^{21}$. Un impacto orgánico también por la luz con la que la entrevista final a Joe Sacco sobre el estatuto de la ficción y del arte se aclara la construcción narrativa e ideológica de la obra. El debate entre ficción y no ficción ${ }^{22}$ legitima la empresa gráfica y la voluntad de reformar las vías del compromiso a la vez que tiñe de activismo la intención de una obra que la propia voz narradora asume como "crónica" y "ejercicio de montaje" (Sagar \& Carrión: 54), es decir como una recomposición subjetiva de la realidad en la cual los autores se comprometen física, gráfica e ideológicamente. Se comprometen mediante la voz que expresan en los

\footnotetext{
${ }^{19}$ El título de la obra podría ser, en efecto, una cita indirecta a Los vagabundos de la cosecha en la cual John Steinbeck reúne una serie de reportajes sobre la exclusión y explotación de las que fueron víctimas miles de jornaleros en tiempos de la crisis agraria del oeste americano en los años 30.

20 "Ahora me busco la vida. Vendo chatarra, pinto grafitti, diseño, hago mis cuadros, escribo canciones" (Carrión y Sagar: 84).

${ }^{21}$ El compromiso artístico se prolonga hasta en el proyecto llevado a cabo por Nuria Güell en colaboración con el Museo de Arte Contemporáneo de Barcelona en 2013, en el cual participaron unos desalojados de la calle Puigcerdà, y con el cual intentó compensar los fallos de los poderes públicos, como lo evoca el prólogo: "con 3000 euros, creó un marco legal que permitía a los chatarreros africanos trabajar y autoemplearse" (Carrión y Sagar: 5).

22 "Sin ficción, tú tienes los hechos, los datos, pero no siempre los puedes conectar. Tú tienes el hecho A y el B, sobre un político corrupto, pero no puedes relacionarlos. Con la ficción puedes hacerlo, esa es su gran virtud: el espectador no tendrá duda alguna sobre la profunda corrupción". O también: "Yo creo que el verdadero new journalism está en el cómic de no-ficción" (Carrión y Sagar: 100-101).
} 
recitativos, cuales recitantes antiguos, transmisores de un saber ${ }^{23}$; se comprometen mediante la abismación del $\operatorname{ver}^{24}$ que une lo personal a lo colectivo, lo íntimo a lo profesional, lo diegético a lo real, lo espontáneo a lo analítico. El salto de la mirada demiúrgica sutilmente neutra a la mirada insaciable y mordaz de la figura periodística crea así las condiciones de un compromiso proteiforme 25 .

\section{Barcelona en colores}

Lejos de la opinión de McLoud ${ }^{26}$, la cromatización del iconotexto, "suplemento de ser" según Groensteen ${ }^{27}$, aboga por la asunción de la subjetividad y de la carga connotativa de la representación. Actúa como factor de cohesión microestructural, creando una unidad para cada testimonio, y participa, a nivel macroestructural, de la construcción artrológica de la coherencia del conjunto, entorno en particular a la representación de Barcelona ${ }^{28}$. Muy representado, el mercado de los Encantes plasma la problemática de la renovación de Poblenou y la elaboración de una polémica "Marca Barcelona" a expensas de las poblaciones en dificultad. Más que el temático, el eco cromático es sugestivo: la presencia marcada de tonos rojos, amarillos y azules, denotaciones de un suave amanecer o de un cálido atardecer, no dejan de recordar la estelada y de insistir así en el anclaje profundo de la diégesis en una sociedad catalana contemporánea sintetizada a través de la imagen de su capital, con sus monumentos, sus calles abandonadas, sus fachadas desconchadas, sus bares o su metro. Tentacular y global, atractiva y repulsiva, absorbe a los indigentes como los hornos absorben

\footnotetext{
23 "Il arrive parfois que le récitant retrouve les accents épiques des conteurs d'autrefois [...] Cette intervention du conteur dans le déroulement de l'histoire recrée une sorte de relation primitive dans laquelle les anciens de la tribu transmettaient le savoir humain par la parole. Cette tradition orale que l'arrivée du livre avait tuée tend à revivre dans la bande dessinée" (Pernin: 46 y ss.).

${ }^{24}$ Véase, por ejemplo, las láminas 67,70 ó 71.

${ }^{25}$ Este salto es particularmente perceptible en las láminas 10 a 15.

26 "La couleur, outre l'effet réaliste qu'elle procure, est un élément d'objectivation de la représentation et [elle] peut être utilisée pour donner du sens, suggérer des sensations" (McLoud: cap. 8).

27 "en libérant la couleur, l'image BD a gagné une matérialité nouvelle, et quelquefois trouvé un supplément d'être" (Groensteen: 31).

28 Las dobles páginas evocadas son 6-7, 24-25, 60-61, 94-95.
} 
la chatarra, para luego escupirlos. No sin razón el alegato de Carrión y Sagar se termina por ese paseo ya mencionado de la chatarra por la ciudad, que termina en un buque que se aleja de una ciudad en parte difuminada tras los escándalos de la chatarra.

\section{Circularidad e ironía}

El protocolo establecido por una narración desdoblada entre microestructuras cohesivas y macroestructura coherente implica la enunciación entera y, consecutivamente, al autor si me refiero a los análisis de Jacques Samson según quien la diegetización de la figura autorial no inhibe el compromiso del autor (Samson: 257) ${ }^{29}$. La clave de lectura, para el lector, es sin duda la ironía que nace de la perspectiva así generada. Las páginas de cuaderno, que con mayor sinceridad gráfica asumen su exogeneidad, contienen cargas irónicas evidentes, sacadas de una mera descripción factual. Si bien la primera no es más que una contextualización ${ }^{30}$, la segunda, valiéndose de una breve historia del carrito de la compra, repasa décadas de un declive económico excluyente. Invierte la relación tensiva de lo veraz, aislando el resplandor pasado del objeto en una foto, cuando el dibujo conota la terrible realidad y denuncia el cinismo de una felicidad obsoleta ${ }^{31}$.

\footnotetext{
29 "Cette forme de collaboration implique un dispositif fondé sur l'omniprésence d'un narrateur que sous-tend une énonciation entièrement tournée vers lui, un peu comme dans des projets documentaires. Si l'auteur de la bande dessinée peut donner l'impression de s'être désinvesti dans le propos, qu'il relègue explicitement à la subjectivité de ses témoins, il n'en va pas de même de sa prise en charge du récit à travers une forme personnelle d'écriture de bande dessinée. Ce qui revient à reconnaître qu'il s'est commis dans l'énonciation".

30 "Poblenou es el laboratorio donde la vieja Barcelona se va transformando en la nueva" (Carrión y Sagar: 22).

${ }_{31}$ Observar la lámina de la p. 73.
} 


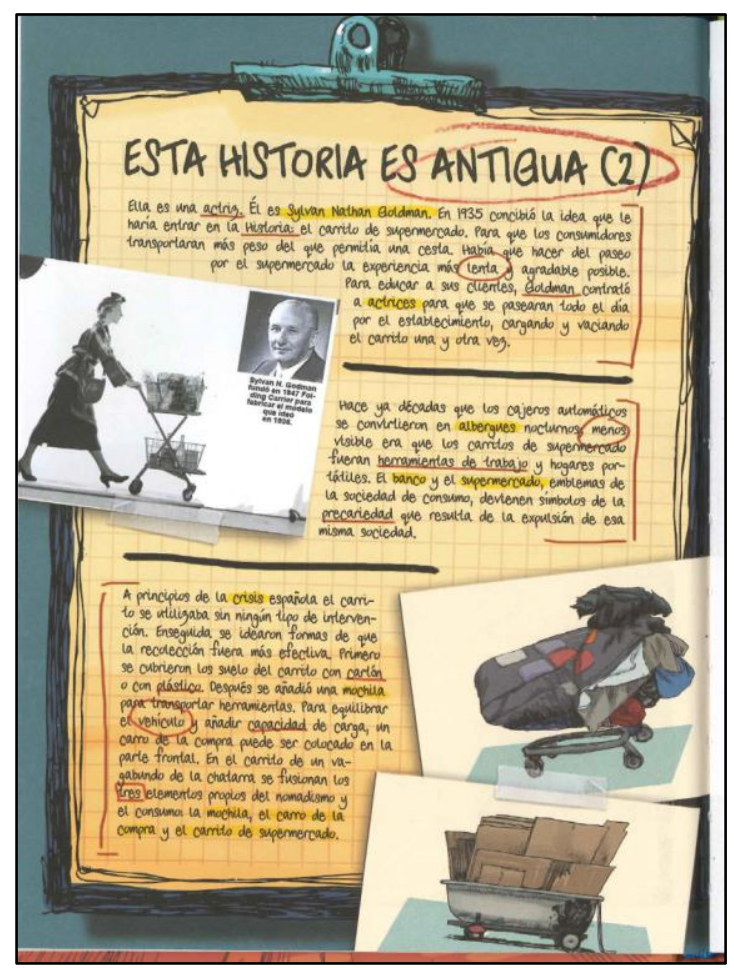

Fig. 7. ( ) Norma Ed. 2015.

La tercera, con el ejemplo de la Fundación Maite Iglesias Baciana, propietaria de la nave en Puigcerdà, entre cuyas dedicaciones humanitarias está el apoyo a poblaciones africanas pero cuyos miembros invierten en el tratamiento de la chatarra o brindan ayuda, mediante la Fundación la Caixa, a los desalojados, apunta la ironía de los grandes consorcios. Esas anécdotas cercan a los necesitados dentro de la circularidad imparable de un sistema que se nutre de sí mismo con la complicidad ciega de los poderes públicos. Una circularidad que trasuda en las postreras viñetas: la chatarra abandona el puerto de Barcelona mientras los tuits inicialmente encauzados a la legitimación de los desalojos apuntan finalmente con una irrisión desconcertante la calidad del mar aquel día o la alegría de las festividades venideras ${ }^{32}$.

\section{Conclusión}

El cómic es un "espejo del mundo", decía Lacassin, y añade que "el contexto \#Mercé13, Ferrán Adrià, destaca que las fiestas serán un mensaje de optimismo". 
socio-político formatea la historicidad cultural del cómic" (Porret: 21), como para machacar la relación entre el cómic y sus instancias narrativas a su contexto. Explotando los recursos propios del iconotexto, el cómic de no ficción de Carrión y Sagar hace cruzarse realidad y diégesis en la elaboración de un proyecto cuyo compromiso se percibe tanto a nivel de su construcción interna como de su resonancia extratextual. Youri Lotman consideraba que el texto siempre se incluye en un contexto y funciona como contrapeso de elementos estructurales extratextuales (Lotman: 35$)^{33}$. Gracias a la ambigüedad narrativa generada entorno al eje de la abismación y posibilitada por la ambivalencia del cómic como arte de la discontinuidad semántica (serie de selecciones) y de la continuidad semiótica (homogeneidad de los lenguajes), los autores innovan en la vía del periodismo gonzo. Conectan el mundo referencial con la diégesis, de modo que aquel influencie la representación de esta, y esta difunda claves de intelección de aquel. El vértigo narrativo - producto espontáneo del iconotexto en este caso- estremece las fronteras del relato y enfoca, literal y metafóricamente, con la distancia irónica, las aporías de un sistema que solo puede modernizarse reciclando sus propios escombros.

\section{Bibliografía}

BRICco, Elisa (2014). "Le roman graphique et l'Histoire: pour un récit engagé", Cahiers de Narratologie, ก.- 26, 01 de octubre de 2014, en http://narratologie.revues.org/6864 [22 de julio de 2015]

BARTHES, Roland (1964). "Rhétorique de l'image", Communications, n.. 4, Recherches sémiologiques, pp. 40-51.

BARTHES, Roland (1968). "El efecto de realidad", Communications, n. 0 11, Trad. Beatriz Dorriots, 1972 para la 2a edición de la traducción, pp. 95-101.

CARRIÓN, Jorge; FoRNIÉS, Sagar (2015). Barcelona. Los vagabundos de la chatarra. Barcelona: Norma.

Fresnault-Deruelle, Pierre (2011). Hergéologie. Cohérence et cohésion du récit en images dans les aventures de Tintin. Tours: Presses Universitaires François Rabelais, Iconotextes.

GravetT, Paul (2011). "Joe Sacco en Palestine: du témoin à I'historien". En Viviane Alary y Benoît Mitaine (ed.), Lignes de front: bande dessinée et totalitarisme. Chêne-Bourg: Georg, pp. 245-254.

\footnotetext{
33 “Le texte en règle générale n'existe pas à lui tout seul, il est nécessairement inclus dans un contexte (historique réel ou de convention). Le texte existe comme contrepoids d'éléments structuraux extra-textuels, il est lié à eux comme le sont les deux termes d'une opposition".
} 
Groensteen, Thierry (2005). La bande dessinée: une littérature graphique. Paris: Milan.

HELBO, André (1975). Sémiologie de la représentation. Théâtre, télévision, bande dessinée. Bruxelles: Complexe.

LOTMAN, Youri (1973). "Texte et hors-texte", en Collectif CHANGE, Transformer, Traduire. Mallarmé: traducteur traduit, n.ำ 14. Paris: Seghers / Laffont, pp. 33-43.

McLoud, Scott [1992] (2000). L'art invisible. Comprendre la bande dessinée. Trad. Dominique Petitfaux. Paris: Vertige Graphic.

PERNIN, Georges (1974). Un monde étrange: la bande dessinée. Paris: Clédor.

PORRET, Michel (2009). "La bande dessinée éprouve l'histoire". En Michel Porret (ed.), Objectif bulles. Bande dessinée et histoire. Chêne-Bourg: Georg, pp. 11-42.

SACCO, Joe (2012). Reportages. Paris: Futuropolis.

SAMSON, Jacques (2011). "Le sujet de la guerre en bande dessinée". En Viviane Alary y Benoît Mitaine (ed.), Lignes de front: bande dessinée et totalitarisme. Chêne-Bourg: Georg, pp. 255-268.

XAvier, José-Manuel (2003). La poétique du mouvement suivie du Carnet de l'animateur. Angoulême: Centre National de la Bande Dessinée et de l'Image.

Fecha de recepción: 6 de abril de 2016

Fecha de aceptación: 8 de septiembre de 2016 